\title{
Searching for new development in areas of the city
}

\author{
Marta Skiba ${ }^{1}$, Anna Bazan-Krzywoszańska ${ }^{1 *}$, Wojciech Eckert $^{1}$, Maria Mrówczyńska ${ }^{1}$, \\ Matgorzata Sztubecka ${ }^{2}$ \\ ${ }^{1}$ University of Zielona Góra, Faculty of Civil Engineering, Architecture and Environmental \\ Engineering, 1 prof. Z. Szafrana St., 65-516 Zielona Góra, Poland \\ ${ }^{2}$ University of Science and Technology, Faculty of Civil and Environmental Engineering and \\ Architecture, 7 prof. S. Kaliskiego St., 85-796 Bydgoszcz, Poland
}

\begin{abstract}
The reason of shaping and building cities is primarily to improve the quality of life of inhabitants. Changes in space in cities concern not only their basic functioning principles but also the transformation of structures and systems (green areas, communications andother). Regardless, spatial policy is based on the continuous search for new services and economic activity to raise standards. The article describes a study which makes an attempt to identify the main desired features that can be taken into account while formulating concepts for planning and designing a prospective city. The study was intended to analyze terms promoted in literature or labels of a desired city, that shape the aspirations of future inhabitants. The city's image-building activities concern the future measured in economic, social and environmental effects. Modelling the future potential concepts of a city development as part of planning for its development, is one of the ways of thinking about the future. Using mathematical and spatial models for this purpose, we acquire knowledge on the possible variants of the city development, as well as measurable effects of this type of phenomena
\end{abstract}

\section{Introduction}

Cities have always been seen as centers of commerce, culture and innovation. Today, cities are centers of population growth, consumption and the use of resources $[1,2]$. Cities attract people by offering citizens better economic opportunities and infrastructure. In both the developed and developing countries, a significant number of people migrate from rural to urban areas every day. With the growth of cities, its influence on the surrounding environment is increasing. Although cities are currently make up only $2 \%$ of the Earth's surface, they use about $75 \%$ of the world's natural resources, produce $70 \%$ of all waste and emit approximately $70 \%$ of the greenhouse gas emissions in the world [3]. Cities are also subject to the undesirable consequences of global climate change$70 \%$ of cities are affected by the adverse effects of climate change [1]. The socio-

* Corresponding author: A.Bazan@aiu.uz.zgora.pl 
economic disproportions that increase the polarization of the quality of lifein cities are also growing [4]. Planning for urban development therefore requires attention not only to deal with the effects of natural phenomena, such as climate change, but also to the changing social and economic landscape. Concerns about the proper development of urban areas should be taken into account when selecting the purposes of spatial policy and discussion on relevant forums, so as to consider sustainable development. Contemporary Polish cities, mostly of the traditional center layout, are developed with new communication systems and their peripheral zones are being developed with new spatial structures related to commercial, service, recreational and educational facilities. New sites outside the organized urban zone are being searched for the sake of a city development. New investment areas are being served with utilities even to the detriment of green areas and forestry. Over the years, various labels have appeared in literature that have been used to conceptualize ideal cities, such as: Garden City [5], Creative City [6], Global City [7], Compact City [8], Liveable City [9], Low-to-Zero Carbon City [10], Regenerative City [11], Smart City [12], Age-friendly city [13], Eco-city [14], Zero Waste City [15], and so on. Such labels highlight the distinct concepts of cities, promoting the characteristics defined by their form, the political and economic structure, social and cultural aspects, and environmental and technological aspects. The above concepts, relating to the characteristics and city definitions, are associated with strategies to reduce urban sprawl, promote better use of existing infrastructure and services - also communication between the places of residence and employment and concentration of services [16]. Population growth and increasing urbanization are causing a number of technical, social, economic and organizational problems, that threaten sustainable economic and environmental development of cities. Rapid development, which several cities have faced, has caused congestion, pollution and an increase in social inequalities [17]. The concept and the labels relating to the development, construction and structure of cities have become widely accepted synonyms of combining different concepts of spatial planning in urban politics [18]. Models of monocentric development with a high density and concentration of employment and residence are the ones which are defined most often. However, there is no general consensus as to the importance of the terms used or the attributes that characterize them. Nevertheless, there is a widespread belief that the new labels are characterized by the pervasive use of information and communication technologies (ICT), which in different urban areas help cities to make better use of their resources. The growth of cities is mostly regulated through the promotion of relatively high density, controlling the intensity of the city land use structure, supported by an efficient public transport system and increase in pedestrian and cycle traffic [19]. Building the concept of an "ideal" city takes place as a consequence of changes in land use [4, 18, 19, $20,21]$ and a policy to promote, inter alia:

- change in the intensification, consolidation, split, and merge and change in the density of urban structure (especially around the inner suburbs),

- development, regeneration and land-use change of post-industrial parts of a city,

- changes in urban land use intensity,

- changes to the structure of residences through higher degrees of availability and zoning existing buildings,

- changes through higher degrees of protecting and zoning the availability of green areas,

- residential density changes associated with another re-urbanization,

- changes in the speed of the development of urban public transport,

- keeping intelligent systems, IT monitoring and social communication. 


\subsection{Zielona Góra - the direction of the city's construction?}

Zielona Góra, because of its surrounding forests, is considered by its residents as one of the most attractive places of residence in Poland [22, 23]. The surrounding forests, like city walls in the past, form a modern development barrier. The constant search for and use of the new investment and residential areas causes the irreversible depletion of forests around Zielona Góra [24]. Deforestation for city development is most common near the already existing buildings, which consequently results in permanent moving green areas away from the city center. Zielona Góra, a city county, formerly the capital of Zielona Góra Voivodeship, and today the seat of the local authorities of the Lubuskie Voivodeship, on 1 January 2015, expanded its territorial area joining the adjacent rural municipality. Because of this fact it reached the sixth position in the standings of the surface of Polish cities in their administrative borders. A combination of a medium size, medium intensity and dense city with a rural community characterized by low intensity, carries a huge risk of an uncontrolled increase of the developed area. In strategic documents, the development of Zielona Góra was based on a plan for sustainable development. It also implies the adoption of the long-term consistent policy of protection and management of forests. City program documents often refer to the need for: preservation of greenery systems, prevention of anthropogenic impact, improvement of landscape resources and "increase the attractiveness of the natural environment, as the element of the city image and a factor that attracts tourists and investors"[25]. Over the years, the foregoing records have been defunct, and in the current city they may be dominated by continuous development along existing roads; which is mainly a result of the current prevention of investment areas that meet the present needs and expectations of investors. Because of the merging of the city and rural municipality of Zielona Gora, the stimulation of local development requires monitoring occurring phenomena and the appropriate allocation of funds. The urban spatial policy must be based on specific implementation tools, and detailed defining objectives that result in the intended effects. To make them happen, it is essential to use tools or instruments of policy implementation. These are techniques for decision-making based on documented data (e.g. indicators) and various central laws and shaped regulatory parameters, and foresight processes (on the basis of the indicators) associated with the preparation of plans. Indicators (indexes) determine the interpretation of a status, or trend, describe components or processes in a real-world environment of the building, the settlements and the city. In this context, they involve the issues of: data collection and standardization, a space scale and a time scale.

\section{Methodology}

\subsection{FCM - Fuzzy Cognitive Maps}

The presented test method refers to the application of Fuzzy Cognitive Maps, which had been presented by Kosko [26, 27]. The first objective of the application of FCM (fuzzy cognitive maps) since their invention was the creation of tools to solve complex political, economic or social problems, available to a wider audience. FCM were supposed to be common eagerly and used. Uncertain causal knowledge is stored in the fuzzy cognitive map, and nodes represent variable phenomena or fuzzy sets [28]. FCM node transforms weighted and summarized input data in numeric data, similar to the artificial neuron model. Unlike expert systems, which are usually classification trees, FCM are nonlinear dynamic systems. FCM are considered to be a simple form of recursive neural networks that in recent years, have often been used as research modeling and requesting tools. The concepts in cognitive maps are equivalent to neurons, but 
outside neurons, they are neither "on" (=1) or "off" $(=0$ or $=-1)$, but may take the states between them, and therefore they are "fuzzy" in the form. Fuzzy concepts are nonlinear functions, which convert activated paths ("causes") into the value in the set $[0,1]$ or $[-1,1]$. When the directional neuron affects all concepts that are dependent on it - the concept may change its status depending on the direction and magnitude of this effect and at the threshold level for specific concepts, consequently they can change the status, and activate the following concepts within the network.

Because the FCM allow for feedback, the newly activated concepts can affect the conce pts that were previously activated. As a result, the activation is spread in a non-linear way through FCM network until the system reaches a stable cycle or a fixed point. FCM is a very dynamically developing direction of research. As mentioned earlier, Fuzzy Cognitive Mapping presents causal links between concepts in the form of graphs. The use of FCM is intuitive, with modeling tools such as: participatory, they may be used to create virtual agents with sophisticated decision-making processes. Shown below, are scenarios in "the quality of landscape management" model in which factors affecting objectives in the policy were strenghtened (weighted).

\section{Extracted variables}

For this research, the following popular labels for an in-depth analysis have been selected:

- Compact City referred to as an emphasis on urban structure compactness in the spatial policy, an increase in the quality use of land and the importance of pedestrian and cycle transport and the accessibility of green areas.

- Eco-city referred to as the growth of urban land use intensification, intensiveness of services and urban transport development.

- Smart City referred to as a focus on the rise of social communication based on the use of intelligent transport systems, monitoring access to all the services in the city.

A list of variables have been extracted, based on conducted interviews, in which factors assessing the quality of city construction and development policy were listed (Table 1).

Table 1. The binding force (power) between variables extracted by experts.

\begin{tabular}{|c|c|c|c|}
\hline variables & environmental & social & economical \\
\hline $\begin{array}{c}\text { changes to the intensification of the } \\
\text { urban structure }\end{array}$ & small & large \\
\hline $\begin{array}{c}\text { development, regeneration of post- } \\
\text { industrial parts of a city; }\end{array}$ & large & average \\
\hline changes in urban land use intensity; & small & average & average \\
\hline $\begin{array}{c}\text { protecting and zoning the accessibility } \\
\text { of green areas }\end{array}$ & large & small & average \\
\hline changes in the population density & average & average & large \\
\hline $\begin{array}{c}\text { IT monitoring and social } \\
\text { communication }\end{array}$ & small & laverage & large \\
\hline development of transport & small & average & average \\
\hline
\end{tabular}

Extraneous variables (different names of factors in the same category, etc.) have been eliminated. The subjective connecting of variables in larger categories on the basis of common characteristics are called qualitative aggregation. When two variables represented opposite directions of the same concept, the polarity of the reverse impacts was consistent with accepted practices [17]. The adopted dependencies between variables were set as strong 0.75, medium 0.5 and low 0.25 [29]. Centrality, which is a measure of the connections of a category with other categories on the map, as well as the overall 
strength of these connections has been calculated as the sum of the absolute values in the column of matrix connections put in and out of a particular category (the sum of the absolute values in a row in the matrix), which was presented by Özesmi [30]. The model has been aggregated as a mutual structure of three factors: economic, natural and cultural influence on each other. Interactions between the factors are presented as negative (brown) or positive (blue) graphs of variable values. In the scenarios, the role of the groups of factors as possible strategic objectives of spatial policy was strengthened or weakened.

\section{Results}

Below, Fig. 1 presents a model that explicitly represents the heterogeneous decisionmaking processes (e.g. is based on the beliefs and experiences), which may predict the socio-environmental consequences of the aggregated behaviors of individuals. The factors are divided into three classes: environmental, social and economical. Then the variability of connections between the basic components and the rest of the category, that affects the exact nature of the results were examined by experts.

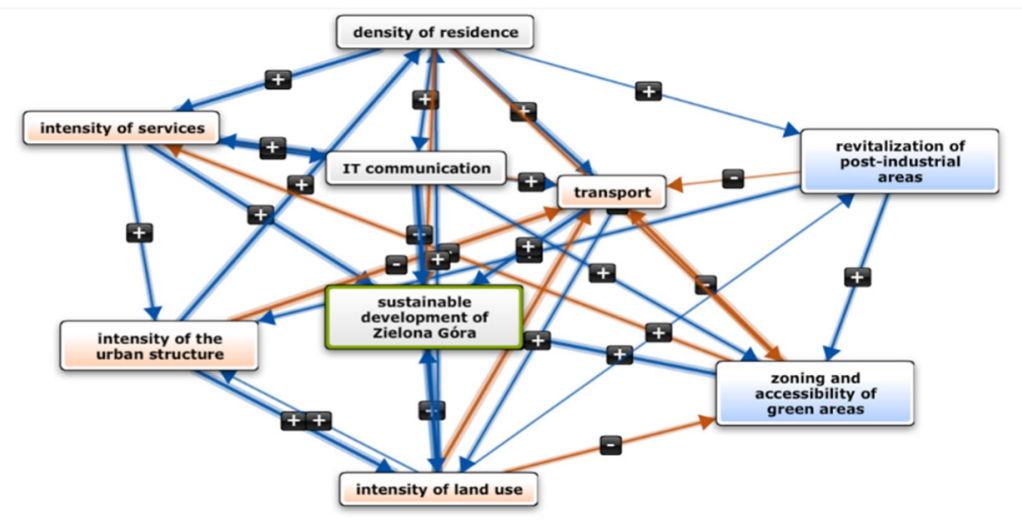

Fig. 1. FCM model of connections of variables for the sustainable development of Zielona Góra [Made using the program: Mental Modeler].

\subsection{FCM for Zielona Góra}

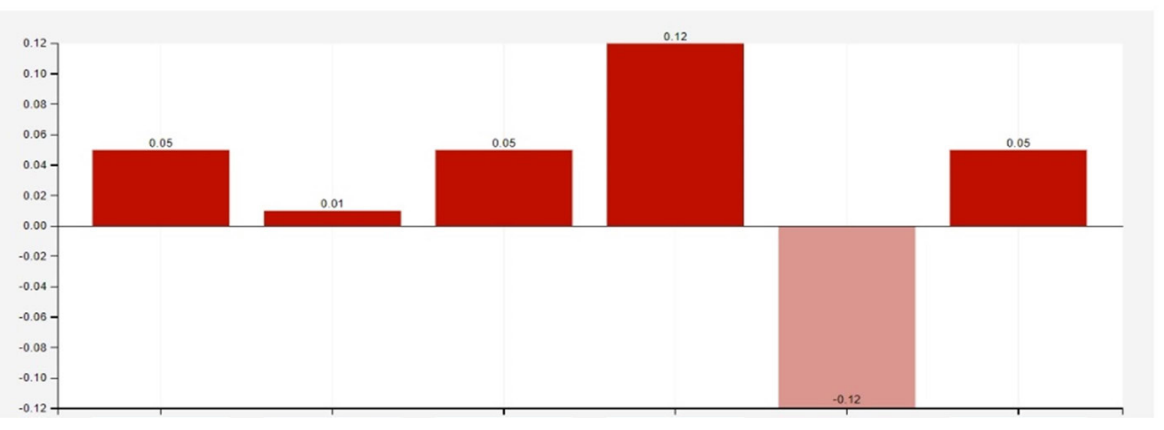

Fig. 2. Scenario of building a Smart City model for Zielona Góra [Made using the program: Mental Modeler]. 


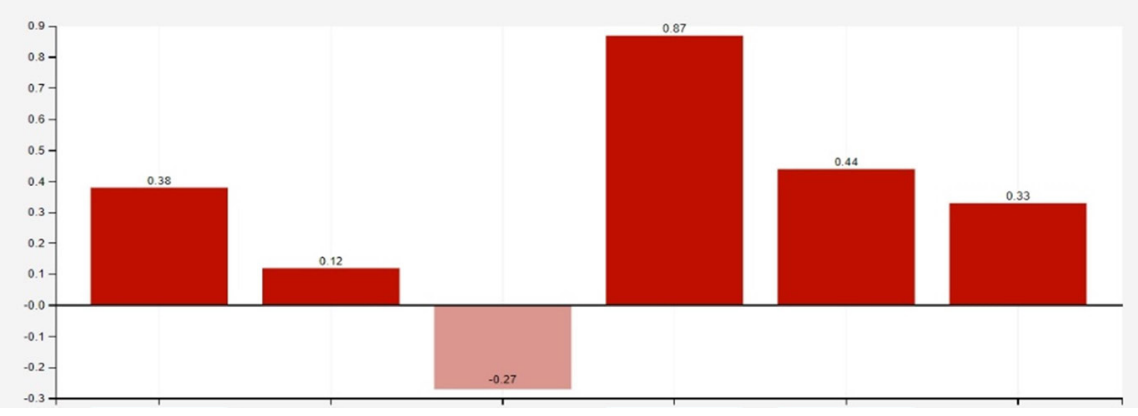

Fig. 3. Scenario of building an Eco City model for Zielona Góra [Made using the program: Mental Modeler]

By analyzing the results of the scenarios presented in the schematics $(2,3,4)$, we can conclude that:

- Fig. 2-a spatial policy emphasizing protecting natural factors and zoning the accessibility of green areas, as well as the intensification of services and IT monitoring and social communication, which in this scenario was synonymous with the construction of a Smart City, results in the importance of the communication network being diminished, which can benefit the urban structure intensity, population density and intensity of land use. At the same time, we can notice the positive aspects of such a determination of policy objectives for the overall sustainability of Zielona Góra and for the regeneration of post-industrial areas .

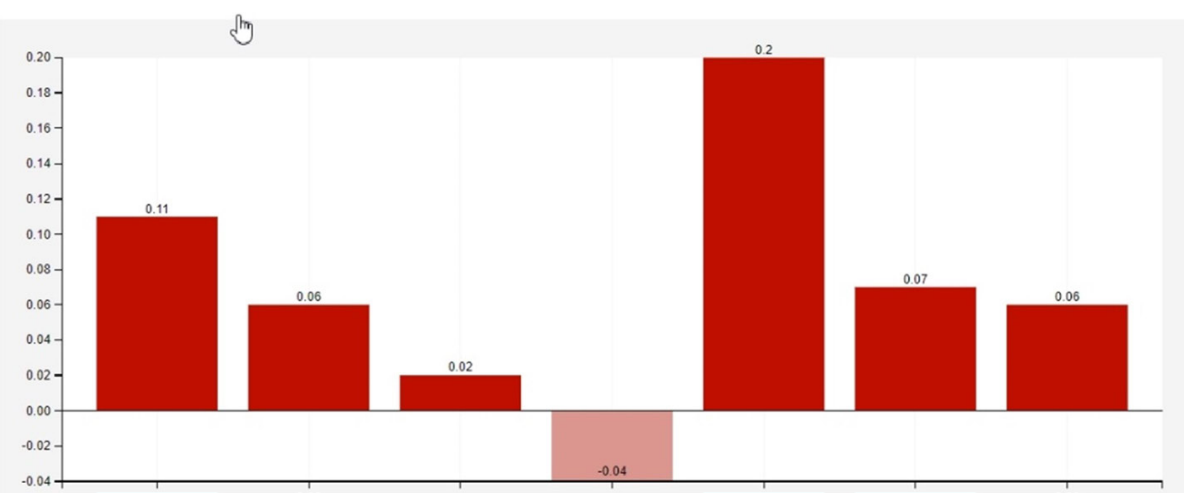

Fig. 4. Scenario of building a Compact City model for Zielona Góra [Made using the program: Mental Modeler].

- Fig. 3 - a city management policy emphasizing the growing importance of economic factors, that is, the intensity of land use, the intensity of services and transport, causes an increase in population density and the intensity of urban structure. At the same time, we can notice the increasing importance of social communication IT and monitoring changes in land use, while reducing the importance of green areas and their accessibility.

- Fig. 4 - with a development policy emphasizing the intensification of land use and the development of public transport, which can contribute to building a Compact City model, we can notice a positive similarity of such policy objectives for the growth of the sustainable development of Zielona Góra. There is an increase in the intensity of services and population density in the city. The disadvantages are, however, factors affecting the accessibility of green areas. 
In all scenarios, Fig. 2, 3, 4 of the city management policy, there is an increase in the importance of correctly adopted trends for sustainable development in terms of planning. With the presented scenarios the perspective changes concerning interested parties can be examined during the consulted decision-making. The dynamics of the problem can also be presented which may be used to test various scenarios. In other words, it needs to be emphasized that the resources management is a dynamic decision-making process including many actors, and with the FCM a multiple aspect of the problem can be captured.

\section{Conclusion}

The preparation of easy-to-use development scenarios, useful for municipal government, local administration, planners and for the institutions that determine regional and global development strategies, has become a necessity.

Empirical data on informal urban development and modernization are quite rare. In this situation, the modeling study may be helpful for an overall understanding of the system [31]. What is more, the study of modeling allows analyzing the effects of various configurations of modernization programs in a comparable way, while avoiding the ethical aspects of experiments in the real world. Agent-based models (FCM) are a useful approach to simulate the effects of modernization interventions in cities to change the living conditions of their inhabitants. In FCM, residents of a city can be represented by individual decisions and their interactions with other residents and their environment.

\section{References}

1. C40 Cities. http://www.c40.org/ending-climate-change-begins-in-the-city (Accessed date: 2018.04.25)

2. Urban Solutions for a Living Planet (Accessed date: 2018.04.25) http://wwf.panda.org/what_we_do/footprint/cities/urban_solutions/why_cities/

3. The Ramsar convention on wetlands. Background and context to the development of principles and guidance for the planning and management of urban and peri-urban wetlands (2012) (COP11 DR11) [online]. Retrieved from: http://www. ramsar.org/pdf/cop11/doc/cop11-doc23-e-urban.pdf, (Accessed date: 2018.04.25)

4. M. Schlüter, A. Baeza, G. Dressler, K. Frank, J. Groeneveld, W. Jager, M. Janssen, R. McAllister, B. Müller, K. Orach, N. Schwarz, N. Wijermans, Ecol Econ 131 (2017)

5. E. Howard, Garden cities of tomorrow (S. Sonnenschein \& Co., Ltd, 1902)

6. M. d'Ovidio, A.R. Morató, City, Culture and Society 8, (2017)

7. H. Ichikawa, N. Yamato, P. Dustan, Procedia Engineering 198 (2017)

8. V. Whitford, A.R. Ennos, J.F. Handley, Landscape Urban Plan 572 (2001)

9. D. Hunt, L. Makana, I. Jefferson, C. Rogers, Tunn Undergr Sp Tech 55 (2016)

10. S. Kennedy, S. Sgouridis, Energ Policy 399 (2011)

11. G.Thomson, P. Newman, Resour, Conserv Recy 132 (2018)

12. B.N. Silva, M. Khan, K. Han, Sustain Cities Soc 38 (2018)

13. S. Steels, Cities 47 (2015)

14. A. Mersal, Procedia Environmental Sciences 37 (2017)

15. A.U. Zaman, S. Lehmann, City, Culture and Society 24 (2011)

16. L. Bourdic, S. Salat, Build Res Inf 404 (2012)

17. S-R. Kim, J. Lee, B. Park, Y. Sano, Discrete Appl Math 201 (2016)

18. G. Denis, P. Parker, Renew Sust Energ Rev 13 (2009)

19. N. Schwarz, Landscape Urban Plan 961 (2010)

20. Z. Ziobrowski, Urbanistyczne wymiary miast (Instytut Rozwoju Miast, 2012) 
21. I. Skrzypczak, W. Kokoszka, J. Kogut, G. Oleniacz, Book Series: IOP Conference Series-Earth and Environmental Science 95 (2017)

22. E. Bagiński, Planowanie przestrzenne, zarys metod i technik badawczych (Oficyna Wydawnicza Politechniki Wrocławskiej, 1994)

23. A. Bazan-Krzywoszańska, Rozwój społeczno-przestrzenny Zielonej Góry po 1945 roku: dynamika rozwoju od miasta małego do miasta średniej wielkości (Oficyna Wydawnicza Uniwersytetu Zielonogórskiego, 2013)

24. M. Skiba, A. Bazan-Krzywoszańska, Czas. Tech.: Architektura 10714 (2010)

25. M. Świąder, S. Szewrański, J. Kazak, Procedia Engineering 161 (2016)

26. B. Kosko, Int J Approx Reason 24 (1988)

27. B. Kosko, Readings in Fuzzy Sets for Intelligent System (1993)

28. S. Gray, J. de Kok, A. Helfgott, B. O'Dwyer, R. Jordan, A. Nyaki, Ecol Soc 202 (2015)

29. F. Harary, G. Gupt, Math Comput Model 257 (1997)

30. U. Özesmi, S. Özesmi, Ecol Model 176 (2004)

31. D. Roy, M.H. Lees, B. Palavalli, K. Pfeffer, P. Sloot, Environ Model Softw 59 (2014) 